Kuhn, Thomas

\title{
Prólogo de T. S. Kuhn a la traducción inglesa de Entstehung und Entwicklung einer wissenschaftlichen Tatsache de Ludwik Fleck
}

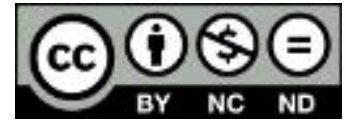

Esta obra está bajo una Licencia Creative Commons Argentina.

Atribución - No Comercial - Sin Obra Derivada 2.5

https://creativecommons.org/licenses/by-nc-nd/2.5/ar/

Documento descargado de RIDAA-UNQ Repositorio Institucional Digital de Acceso Abierto de la Universidad Nacional de Quilmes de la Universidad Nacional de Quilmes

\section{Cita recomendada:}

Kuhn, T. (2010). Prólogo de T. S. Kuhn a la traducción inglesa de Entstehung und Entwicklung einer wissenschaftlichen Tatsache de Ludwik Fleck. Metatheoria, 1(1), 115-118. Disponible en RIDAA-UNQ Repositorio Institucional Digital de Acceso Abierto de la Universidad Nacional de Quilmes http://ridaa.unq.edu.ar/handle/20.500.11807/2391 
La aparición de una traducción inglesa de la obra de Ludwik Fleck -Génesis y desarrollo de un hecho científico- concreta un proyecto que propuse a varios amigos y conocidos (pero no a los editores actuales) desde mi primer encuentro con este libro hace ya un cuarto de siglo. Mi propósito al solicitar una traducción no era simplemente hacer más accesible el trabajo de Fleck a un público angloparlante, sino más bien proveerle una audiencia de la que carecía. En veinticinco años solo encontré dos personas que hubieran leído el libro independientemente de mi intervención. (Uno es Edward Shils, quien aparentemente lo leyó todo; el otro, Mark Kac, que conoció personalmente al autor.) Los editores de esta edición me dijeron que supieron del libro por primera vez cuando yo se los di a conocer. Dadas esas circunstancias, no supe cómo declinar su invitación a proporcionar una nota a la manera de prólogo que refleje mi propio encuentro con Fleck.

Según lo que creo recordar, leí primero el libro durante el año 1949 o a comienzos de 1950. En esos tiempos era un miembro de la Sociedad de Fellows de Harvard que se preparaba para transitar desde la investigación en física a la historia de la ciencia y también, simultáneamente, para explorar una revelación que experimenté uno o tres años antes. ${ }^{1}$ Se me reveló entonces el rol que juegan en el desarrollo científico los ocasionales episodios no acumulativos, a los que desde entonces etiqueté como revoluciones científicas. No había sobre ese tema ninguna bibliografía conocida y mis lecturas eran por lo tanto exploratorias, a menudo debiendo mucho a la serendipia. Una nota al pie de página en el libro de R. K. Merton Ciencia, sociedad y tecnología en el siglo diecisiete en Inglaterra ${ }^{2}$ me condujo a la obra del psicólogo evolucionista Jean Piaget. Aunque el libro de Merton era un obvio desiderátum para un futuro historiador de la ciencia, la obra de Piaget seguramente no lo era. Mucho más insólita fue la nota al pie de página que me condujo a Fleck. La encontré en el libro de Hans Reichenbach Experiencia y predicción. ${ }^{3}$

Reichenbach no era, por supuesto, un filósofo que pensara que los hechos poseyeran un ciclo vital. Cuando cita la lámina en la que Fleck muestra las

\footnotetext{
* Traducción de Kuhn, T.S., "Foreword", en Fleck, L., Genesis and Development of a Scientific Fact, Chicago: The University of Chicago Press, 1979, pp. vii-xi.

${ }^{1}$ Un relato más extenso de la "revelación" se incluye en el prefacio de una reciente selección de mis ensayos, The Essential Tensión: Selected Studies in Scientific Tradition and Change (Chicago, 1977).

${ }^{2}$ R. K.Merton, Science, Technology and Society in Seventeenth Century England (New York, 1970), p. 221 n. La monografía de Merton apareció originariamente en 1938.

${ }^{3}$ Hans Reichenbach, Experience and Prediction (Chicago, 1938), p. 224 n.

(C) Editorial de la Universidad Nacional de Tres de Febrero. Publicado en la República Argentina.
} 
cambiantes representaciones del esqueleto humano, escribe: "Las operaciones intelectuales nos muestran el camino para superar nuestras capacidades intuitivas subjetivas... Cada imagen puede, además de contener características falsas, introducir algunos rasgos verdaderos en la composición". ${ }^{4}$ La posibilidad de que Fleck escribiera estos párrafos no es mayor a la de que Reinchenbach hablara de "génesis y desarrollo de un hecho científico". Pero este era el título de la obra de Fleck y Reichenbach tuvo que incluirlo cuando menciona la lámina. Leyéndolo, reconocí inmediatamente que un libro con ese título parecía hablar de mis propios intereses. El conocimiento del texto de Fleck pronto confirmó esta intuición e inauguró mi no muy sistemática campaña para introducirlo en una audiencia más amplia. Uno de aquellos a quien se lo mostré fue James Bryant Conant, en ese entonces Presidente de Harvard y poco tiempo después Alto Comisionado de Estados Unidos para Alemania. Algunos años más tarde, evoca con júbilo la reacción de un profesor asociado alemán cuando le menciona el título en cuestión: "¿Cómo puede ser un libro así? Un hecho es un hecho. No tiene génesis ni desarrollo". Esa paradoja era, por supuesto, lo que me había conducido al libro.

Me han preguntado más de una vez qué tomé de Fleck y solo puedo responder que me es totalmente incierto. Seguramente la existencia de ese libro me reafirmó en mis convicciones, una contribución nada trivial, puesto que en 1950, y por algunos años más, no conocí a nadie más que viera en la historia de la ciencia lo que yo mismo encontraba en ella. También, muy probablemente, el conocimiento del texto de Fleck me ayudó a darme cuenta de que el problema que me interesaba tenía fundamentalmente una dimensión sociológica. Que es, de alguna manera, el contexto en el que lo cité en mi La estructura de las revoluciones científicas. ${ }^{5}$ Pero no estoy seguro de que haya tomado nada mucho más concreto del trabajo de Fleck, aunque obviamente pude e indudablemente debí hacerlo. En ese tiempo, encontré el alemán que manejaba Fleck extraordinariamente dificultoso, parcialmente porque el mío estaba enmohecido y parcialmente porque no poseía ni el bagaje ni el vocabulario necesario para asimilar discusiones acerca de la medicina y la bioquímica, especialmente cuando eran vistas desde la perspectiva -para mí desconocida y sin embargo vagamente repulsiva- de una sociología de una mente colectiva. Las líneas que tracé en el margen de mi ejemplar del libro sugieren que yo respondí primariamente a aquello que ya había estado muy presente en mi pensamiento: los cambios en las gestalts por medio de las cuales la naturaleza se presenta a sí misma y las dificultades consiguientes en presentar "hechos" independientes de los "puntos de vista". Incluso en ese entonces, comprometido en la exploración de Kohler, Koffka y de otros psicólogos gestaltistas, me resistí (como seguramente pudo sucederle a Fleck) a su frecuente sustitución de "ver cómo" por "ver". Lo que percibo cuando miro el famoso pato-conejo es o un pato o un conejo, pero no líneas

\footnotetext{
${ }^{4}$ Idem.

${ }^{5}$ Thomas S. Kuhn, The Structure of Scientific Revolutions (1962; 2a. ed. aumentada, Chicago, 1970), pp. vi-vii.
} 
sobre la página -al menos no hasta después de mucho esfuerzo consciente-. Las líneas no son hechos de los cuales el pato y el conejo constituyen interpretaciones alternativas.

Releyendo ahora el libro, algo que no he hecho en el ínterin, encuentro muchas intuiciones que pude haber trabajado fructíferamente desde mi perspectiva. Estoy, por ejemplo, muy impresionado por la discusión de Fleck (cap. 4, sec. 4) sobre las relaciones entre la ciencia de revistas y la ciencia de manuales. Esta última puede ser concebida como el origen de mis propios señalamientos acerca de los libros de texto científicos, pero Fleck está interesado en otro conjunto de cuestiones -el carácter personal, tentativo e incoherente de la ciencia de revistas junto con el acto esencial y creativo de los individuos que le añade orden y autoridad mediante una sistematización selectiva en un manual-. Estos asuntos, que se me escaparon por entero, ameritan muchas consideraciones adicionales, no siendo el menor de los motivos el que pueden tener un tratamiento empírico. Nuevamente, dados mis intereses personales, estoy particularmente excitado por los señalamientos de Fleck (cap. 4, sec. 3) sobre las dificultades de la transmisión de ideas entre dos "colectivos de pensamiento" y, sobre todo, por el párrafo final sobre las posibilidades y limitaciones de participar en varias "comunidades de pensamiento". ("Para uno y el mismo problema son usados más a menudo estilos de pensamiento muy diferentes que aquellos que están más cercanamente relacionados. Sucede con mayor frecuencia que un médico prosiga simultáneamente estudios de una enfermedad desde un punto de vista clínicomédico o bacteriológico junto con unos de historia de la civilización a que lo haga junto con unos puramente químicos".) También aquí Fleck abre caminos para la investigación empírica.

Los lectores encontrarán muchas otras aperturas similares en el libro rico y penetrante de Fleck. Aunque mucho ha ocurrido desde su publicación, permanece como una cantera brillante y largamente inexplorada. Pero la posición que elabora no está libre de problemas fundamentales y para mí se agrupan, como me sucedió en la primera lectura, alrededor de la noción de colectivo de pensamiento. Lo que me preocupa no es que el colectivo de pensamiento sea una ficción hipostasiada, aunque pienso que lo es. La propia respuesta de Fleck a esta objeción (cap. 4, sec. 3, n. 7) parece adecuada. Más bien encuentro que la noción es intrínsecamente inconducente y una fuente de tensiones recurrentes en el texto de Fleck.

Brevemente, un colectivo de pensamiento parece funcionar como una mente individual mucho más aguda porque muchas personas la poseen (o son poseídas por ella). Para explicar su aparente autoridad legislativa, Fleck apela repetidamente a términos prestados de un discurso acerca de individuos. Algunas veces escribe acerca de la "tenacidad de sistemas de opinión cerrados" (cap. 2, sec. 3; las itálicas me pertenecen). ${ }^{6}$ En otros sitios da cuenta de esta tenacidad

\footnotetext{
${ }^{6} \mathrm{Al}$ citar este y los siguientes párrafos del texto de Fleck, añadí y sustraje itálicas a voluntad. Los lectores pueden controlar estas modificaciones viendo el texto traducido.
} 
en términos, por ejemplo, de "confianza en los iniciados, dependencia de la opinión pública, solidaridad intelectual" (cap. 4, sec. 3). Respondiendo a esas fuerzas, los miembros de un colectivo de pensamiento vienen a participar en lo que Fleck a veces describe como "una especie de armonía de ilusiones" (cap. 2, sec. 3). Indudablemente, esta última frase es intencionadamente metafórica, pero es una metáfora dañina, porque refuerza la impresión de que, en ausencia de la presión social, la ilusión pudo haberse evitado: "Si los hallazgos (de Siegel) hubieran tenido la influencia apropiada y recibido una medida apropiada de publicidad..., el concepto de sífilis pudiera ser diferente en estos días" (cap. 2, sec. 4; las itálicas me pertenecen).

Otras frases a través del libro de Fleck sugieren una posición muy diferente, que es mucho más próxima a la mía. La fuerza de un colectivo de pensamiento es descripta a veces como una "compulsión" o una "restricción intrínseca" (cap. 3). En otro lugar, Fleck escribe que "la comunicación de pensamientos en un colectivo, más allá de su contenido o justificación lógica, debe conducir por razones sociológicas a la corroboración de las estructuras de pensamiento (Denkgebilde)" (cap. 4, sec. 3). Esta y muchas otras frases en el libro indican que la participación en un colectivo de pensamiento genera efectos que son de alguna manera categoriales o a priori. Lo que el colectivo de pensamiento brinda a sus miembros es algo así como las categorías kantianas, prerrequisitos para cualquier pensamiento. La autoridad del colectivo de pensamiento es así más de índole lógica que social, aunque existe para el individuo sólo en virtud de su participación en un grupo.

Esta posición es, por supuesto, extraordinariamente problemática y los intentos ocasionales de Fleck de desarrollarla distinguiendo entre elementos pasivos y activos del conocimiento son para mí poco esclarecedores. "Pasivo" y "activo" son términos nuevamente tomados de la psicología individual y aplicados a un colectivo. Mucho más útil en este y otros pasajes puede ser la distinción epistémica entre conocimiento y creencia. (Por ejemplo, si "conocimiento" hubiera sido sustituido por "opinión" en la frase previamente citada -"la tenacidad de los sistemas de opinión autocontenidos"-, entonces "tenacidad" e incluso también "autocontenido" y "sistemas" pueden devenir redundantes.) Sin embargo, hacer notar estos problemas centrales no implica desacreditar a Fleck. Las dificultades a las que este párrafo final apunta han sido centrales para la filosofía desde Wittgenstein ${ }^{7}$ y todavía permanecen irresueltas. Haberlas revelado en el material empírico de la historia de la ciencia puede ser un logro suficiente.

Thomas S. Kuhn Junio de 1976

Traducción: César Lorenzano

${ }^{7}$ On certainty (Oxford, 1969) de Wittgenstein es particularmente relevante. 